\title{
Políticas Públicas da Educação: Percursos Íngremes e Sinuosos
}

\author{
Adriana Moura Maial ${ }^{\text {; Theóphilo Michel Álvares Cabral Beserra }}{ }^{2}$
}

\begin{abstract}
Resumo: O presente artigo discute as políticas públicas da educação brasileira, tanto do ponto de vista econômico como político-social, ao relacioná-las as consequências perversas que a ineficiência da escola causa sobre a individualidade do aluno e sobre a sociedade. Atribui essa ineficiência ao ineficaz padrão de gestão e faz recomendação para uma mudança desse padrão no sentido de reforçar a autonomia da escola. Assim, objetiva fazer indicações para um novo padrão de gestão da política educacional e apontar algumas práticas pedagógicas inovadoras diante das dificuldades e necessidades atuais, ao repensar e considerar a educação como dinamizadora de outros processos sociais, para novas formas de organização quanto a objetivos diversos; buscar o efetivo exercício da cidadania ao conhecer e vivenciar problemas concretos considerando os valores humanos e a ética da austeridade.
\end{abstract}

Palavras-chave: Educação; Políticas Públicas; Pedagógico; Inovação; Aprendizagem.

\section{Public Education Policies: Steep and Winding Paths}

\begin{abstract}
This article discusses the public policy of the Brazilian education, both economically and politicallysocial, to relate them the perverse consequences that the inefficiency of school because of the individuality of the student and society. Assigns this inefficiency to ineffective management standard and makes recommendation for a change this pattern to strengthen school autonomy. Thus, aims to make signs for a new pattern of management of educational policy and point out some innovative teaching practices in the face of difficulties and current needs, to rethink and consider education as a dynamic of other social processes, new forms of organization and the various objectives; seek the effective exercise of citizenship to know and experience real problems considering human values and ethics of austerity.
\end{abstract}

Keywords: Education; Public policy; Pedagogical; Innovation; Learning.

\section{Introdução}

Diante do enfrentamento de novos padrões de produtividade e competitividade, a educação é o componente essencial das estratégias do desenvolvimento quanto ao conhecimento, às habilidades e às competências cognitivas e sociais dos indivíduos, que são as matérias-primas vitais para as economias modernas.

Nessa teia de interação intrapessoal e interpessoal, a educação se torna objeto das pautas governamentais, em busca de caminhos para uma reestruturação econômica, social, política e histórica.

\footnotetext{
${ }^{1}$ Mestranda pela Anne Sullivan University. E-mail: adrianamoura.2007@ hotmail.com;

${ }^{2}$ Mestre em Geografia pela Universidade Federal do Ceará, Especialista em Geografia e Meio Ambiente pela Universidade Regional do Cariri, licenciado em geografia pela Universidade Regional do Cariri. E-mail: Mic.beserra@ hotmail.com.
} 
No entanto, há a necessidade de promover reformas nos sistemas educacionais eficientes e equitativas, para uma eficaz cidadania capaz de enfrentar a revolução que está acontecendo na realidade atual.

Para tanto, é preciso adequar as estratégias de desenvolvimento a situações conjunturais caracterizadas por políticas econômicas de curto prazo envoltas de processos de longo prazo como educação; governos autoritários com instabilidade e fragilidade na experiência democrática e grandes desigualdades na distribuição de renda e na oferta de serviços educacionais com os subsídios necessários para o processo educacional. Neste caso, a educação está convocada primordialmente, para associar uma nova relação entre o crescimento econômico com melhores condições de vida e a consolidação dos valores da democracia.

A supracitada constatação, também, tem levado a se repensar o papel da educação como elemento que pode dinamizar outros processos sociais importantes que estão sendo formados pela escolarização formal, bem como a família, os meios de comunicação e outros âmbitos educativos informais, para novas formas de organização quanto a objetivos diversos: preservação ambiental, direito do consumidor, erradicação da violência, fim das discriminações sociais etc.

Ao longo de toda uma trajetória, as coisas não se perpetuam e nem se consolidam, devido a diversas contradições quanto a alguns pensamentos hilários e atitudes preocupantes que são resultados e/ou resultam em constantes transformações, evoluções e, em alguns fatores, involuções; onde o sujeito deixa, muitas vezes, de ser importante e indispensável no processo e passa a condição de descartável ou supérfluo, mero espectador. São os indivíduos a causa do sucesso ou do fracasso de si próprios, de sua própria família, de sua própria escola, de sua própria instituição de fé e, em última análise, de sua própria sociedade. Segundo Ricardo Antunes:

O apregoado desenvolvimento dos processos de 'qualidade total' converte-se na expressão fenomênica, involucral, aparente e supérflua de um mecanismo produtivo gerador do descartável e do supérfluo, condição para a reprodução ampliada do capital e seus imperativos expansionistas e destrutivos. (2005)

Segundo Jean-Jacques Rousseau (1712 - 1778), “todo homem nasce bom e a sociedade o corrompe", mas temos convicção também que o indivíduo influencia o meio ambiente, às vezes, até o destrói em benefício próprio. Assim, o produto de tudo que é produzido nas diversas 
Id on Line Revista Multidisciplinar e de Psicologia

Id on Line Multidisciplinary and Psycology Journal

relações pessoais constitui as crises morais e a desorganização progressiva da sociedade, que nada mais são as crises existenciais, portanto o sujeito é peça fundamental no todo, porque as estruturas sociais, morais, culturais, intelectuais, políticas, dentre outras, se apoiam nele.

No entanto, a efetividade desse exercício da cidadania depende do conhecimento sobre a natureza dos problemas concretos, considerando valores e revalorizando com responsabilidade a ética da austeridade, ou seja, a formação de uma ética de convivência mais solidária.

\section{Educação Básica: Uma Política de Reconstrução}

A educação brasileira está relacionada com as experiências vividas durante o processo de desenvolvimento e ocorre em todo lugar e durante a vida toda, portanto deve estar associada à apropriação das mediações sociais, políticas, históricas e culturais da sociedade.

Partindo do pressuposto de que é preciso preparar todos para integrar a sociedade e diminuir a exclusão, faz-se necessário voltar os olhos para a educação básica, já que a expansão quantitativa de escolas não foi acompanhada de uma reorganização institucional que deveria ter, como foco principal de atenção, a qualidade e as condições do ensino, já que todos os aspectos pertinentes foram decididos em nível central, não em termos de diretrizes básicas.

A escola obrigatória de base mostra o descompasso do sistema com as novas demandas econômicas e sociais, visto que na medida em que se garantiu o acesso à escola, não se garantiu a permanência e a conclusão do ensino obrigatório, nem um atendimento escolar com um padrão socialmente justo de qualidade para todos.

A expansão quantitativa cresceu desordenadamente, houve aumento de recursos burocráticos, investimento na rede física sem prever o aporte permanente para o custeio que é indispensável para manter as escolas equipadas e os recursos humanos necessários - sobretudo o professor- com remuneração digna assegurada.

O desordenamento e os altos índices de fracasso escolar e subescolarização, começaram a aflorar, a partir de segunda metade dos anos 70, com o agravamento da crise econômica e consequente crise de governabilidade, o que "impossibilitou" formular objetivos e políticas estratégicas para reverter o quadro de baixa produtividade dos sistemas de ensino. 
Id on Line Revista Multidisciplinar e de Psicologia

Id on Line Multidisciplinary and Psycology Journal

O planejamento debilitado, diante de um sistema agigantado que incorporava em ritmo acelerado populações extremamente heterogêneas, atuou complementarmente para constituir o padrão caótico de gestão hoje existente: a descentralização do ensino sem prever mecanismos de integração regional, sem definição de metas e com forte influência do clientelismo político e a não continuação e atualização financeira dos convênios, o que reafirma e resulta a inexistência de um sistema holístico e coerente de colaboração entre as instâncias governamentais.

Diante do exposto, pode-se afirmar que o resultante modelo atual de educação não atende as expectativas da sociedade. Como vários estudos indicam, a evasão escolar, seja por abandono ou repetência, cresce exageradamente. $\mathrm{O}$ apelo do mercado informal tornou-se mais poderoso e atrativo, visto que muitos jovens abandonam a escola antes de completar 14 anos e as maiores taxas de evasão ocorrem após cinco ou seis anos de permanência no sistema. É preciso oferecer qualidade no ensino, uma vez que o entrave à universalização do ensino básico não está no número de vagas, mas nas absurdas taxas de repetência, um dos fatores da evasão escolar.

Cabe indagar o que significa uma vaga na escola pública brasileira hoje, em que o princípio da equidade e da eficiência são relegados a segundo plano, a formação de gerações e gerações se consideram fracassadas e incapazes de adquirir habilidades intelectuais básicas e isso é considerado normal pela sociedade e pela mídia, causando um drama cotidiano, cujo efeito dizimador é tão perverso para centenas de milhares de crianças e famílias que se esforçam para mantê-las e se defrontam com o fracasso e incorporam-no a sua vida.

Embora a vaga exista, insere-se em um padrão de gestão fragmentado, descontínuo, desorganizado, agravado pela ineficiência de avaliação de resultados, do não assumir responsabilidades pelo ensino-aprendizagem, no qual há professores mal pagos, despreparados e desmotivados; jornada escolar encurtada por paralizações, recessos, comemorações e incidentas; falta de condições mínimas de trabalho; currículo fragmentado; ausência de integração entre as séries e as disciplinas; infraestrutura em péssimo estado; entre outros aspectos.

Diante deste quadro, há envolta da educação brasileira uma grande carência, na qual tudo deve ser considerado - a ausência de condições de sobrevivência, as drogas, o percurso 
Id on Line Revista Multidisciplinar e de Psicologia

Id on Line Multidisciplinary and Psycology Journal

para a escola, a indiferença de alguns professores e pais, entre outros. O considerar essas prioridades significa promover mudanças significativas em diversos aspectos.

\section{Educação Básica: Integração e Transformação entre Realidades}

Segundo a teoria humanista, é somente mediante a perspectiva da totalidade, que a consciência é entendida. Seu valor reside na relação e na integração entre realidades e entre eumundo.

A educação básica no Brasil não pode ser alicerçada em uma política que não objetiva a aprendizagem do aluno, ora em uma perspectiva assistencialista e/ou ideologizante, ora como uma preparação para vida sem objetivá-la. É preciso ressaltar a principal função da escola que é ensinar e o seu resultado que é a aprendizagem, porque dela devem ser esperados, avaliados e cobrados. Outras funções podem ser assumidas pela escola por imposição de contingências históricas e sociais, porém sua tarefa fundamental é a gestão da relação pedagógica, pela qual o ensino e a aprendizagem se efetuam.

Woolfolk (2000), diz que "ambientes de sala de aula que apoiam a autonomia do aluno estão associados com maior interesse, senso de auto competência e preferência por desafio".

De acordo com Rogers, o ser aprendente deve ser plenamente atuante, pois o objetivo é facilitar a aprendizagem, assim, o homem educado é o que aprendeu a aprender, o que aprendeu a adaptar-se a mudanças e o que sabe que a busca do conhecimento dá base para alguma segurança.

Portanto, deve haver objetivos estratégicos na educação básica para atender as necessidades atuais, dentre elas: a valorização das ideias e valores pertinentes ao exercício da cidadania contemporânea; uma educação integral de qualidade para o preparo pessoal e profissional; a adoção de hábitos de consumo para a austeridade e não apenas para a posse de bens e serviços, enfim, a aquisição de conhecimentos e habilidades cognitivas e sociais básicas, através de um trabalho interativo, que não deve ser confundido com a fragmentação curricular que tem predominado na educação.

As necessidades básicas da educação contemporânea se encaminham para a valorização dos conteúdos mais diversificados e específicos como educação ambiental, preservação do 
Id on Line Revista Multidisciplinar e de Psicologia

Id on Line Multidisciplinary and Psycology Journal

meio ambiente, relações interpessoais e intrapessoais, prevenção no uso das drogas, entre outros conteúdos voltados para a realidade sociocultural local, integrados às disciplinas curriculares em uma forma inovadora e transdisciplinar, sem a fragmentação do tempo escolar em grande número de disciplinas estanques.

As realidades escolares e sócio-regionais não comportam modelos únicos de organização, assim, grande margem de decisão deve ser dada à escola, uma vez capacitada para essa tarefa. O Brasil precisa de uma educação adequada a alunados desiguais socialmente e heterogêneos culturalmente, sobre isso, pouco se vem investindo e investigando. $O$ ato de ensinar um pouco de tudo, e mal, é uma receita para o fracasso, para a repetência.

A repetência é inexplicável pedagogicamente, inaceitável socialmente e improdutiva economicamente, portanto deve ser a prioridade educacional do poder público no Brasil em busca de reverter o quadro e consequentemente a evasão. Para isso requer conhecimento pedagógico e capacidade de gestão político-institucional para entender a heterogeneidade da repetência em contextos socioculturais distintos; articular estratégias de curto, médio e longo prazo na trajetória escolar; dispor de instrumentos diagnósticos para definir o ponto de partida e os possíveis resultados; promover os ajustes necessários para elevar os padrões de qualidade; definir políticas de capacitação da gestão escolar e dos docentes, visando utilizar com competência diagnósticos e avaliações periódicas; estimular a pesquisa educacional voltada para o ensino-aprendizagem da grande massa de repetentes; apoiar ações que se disponham a reverter a situação de fracasso escolar.

\section{Educador e Educando: Elementares da Educação}

Outro fator que cabe ressaltar é a desvalorização salarial do professor, já que, historicamente o professor primário ganhava tanto quanto um juiz, quando a escola primária era privilégio das elites, o que torna inaceitável e inexplicável a deterioração salarial do magistério e ao mesmo tempo reafirma que não há grande empreendimento de esforços para que o professor tenha uma remuneração digna.

O educador precisa de motivação e, assim, motiva os educandos, pois deve nortear o processo educacional ao ser um facilitador, um ser verdadeiro, autêntico, real com seus 
Id on Line Revista Multidisciplinar e de Psicologia

Id on Line Multidisciplinary and Psycology Journal

educandos, despojando-se do tradicional. Deve-se existir uma relação empática, onde haja a compreensão e a aceitação do outro com suas particularidades, ao aprender a ser aprendiz, independente e autêntico; ao ser compreendido e não julgado, pois a avaliação e a autoavaliação são elementos secundários. Segundo Rogers, só uma mudança muito grande na direção básica da educação, pode atender às necessidades da cultura de hoje.

Rogers descreve as aprendizagens e o conhecimento integrados com a vida ao considerar o educando como um todo, sendo um ser consciente e autônomo com liberdade para decidir e com intencionalidade direcionada para um fim. Sua pedagogia é "centrada no aluno", portanto o que importa é a experiência e a responsabilidade do aluno no processo educacional, subsidiado no poder da pesquisa como método de aprendizagem.

A educação brasileira está relacionada com as experiências vividas durante o processo de desenvolvimento e ocorre em todo lugar e durante a vida toda, e não somente na escola. Portanto, cabe ao educador ser um conhecedor das mesmas para um direcionamento mais eficaz para a aprendizagem significativa.

Segundo a Gestalt, os elementos jamais se constituem pela síntese, pois são percebidos em conjunto, não existem dados isolados, mas constituídos sempre em totalidades organizadas. Assim, a aprendizagem é uma reorganização do cognitivo, permitindo a compreensão de um problema e sua solução.

O desenvolvimento só é promovido mediante o impulsionamento das relações sociais, quando promovem os educandos para além do que já sabem, em lugar de trabalharem somente com o que já é conhecido, pois o todo é constituído pelas partes, mas as partes não são constituídas pelo todo. Como expressa Saviani:

(...) a educação é, sim determinada pela sociedade, mas que essa determinação é relativa e na forma da ação recíproca, o que significa que o determinado reage sobre o determinante. Consequentemente, a educação também interfere sobre a sociedade, podendo contribuir para sua própria transformação. (2008, p.93).

Com embasamento nas teorias supracitadas, pode-se afirmar que a aprendizagem é um processo constante e ininterrupto que depende das situações do dia a dia, enquanto o desenvolvimento é associado às resultantes transformações devido às experiências vivenciadas ao longo da vida. Ambos acontecem desde que nascemos, ou mesmo antes, e são processos complexos. 
Id on Line Revista Multidisciplinar e de Psicologia

Id on Line Multidisciplinary and Psycology Journal

\section{Processo Educacional: Ações Partilhadas e Compartilhadas}

A aprendizagem e o desenvolvimento não dependem apenas da ação do mundo externo sobre o educando, mas também da ação do mesmo sobre o mundo, são trocas que constroem ideias particulares do mesmo sobre esta realidade. É uma busca constante de (re) conquistar seu espaço com humanidade e dignidade. Ele deve ser visto como ativo e não passivo no processo de aprendizagem.

Sabe-se que cada educando possui suas particularidades, características que lhes são próprias, que o fazem comportar-se diferente em diversas situações: aprender de forma mais rápida ou mais lenta, ter atitude positiva ou negativa frente à vida. $\mathrm{O}$ ambiente em que ele está inserido, seu contexto social, econômico e cultural e também suas relações na família, na escola e no trabalho, são aspectos contextuais extremamente relevantes a serem considerados na análise do processo de ensino-aprendizagem. É a busca do bem-estar social.

O desenvolvimento não é promovido de todas as interações, mas daquelas que parte do conhecimento do aluno, das que o levam a pensar e a fazer além do que já pensa e faz. É necessário efetivar experiências e ações promotoras de aprendizagem, que não incidam sobre o educando unilateralmente, de fora para dentro e construir e legitimar um novo senso comum sobre a educação, o trabalho e a própria individualidade. Quebrar paradigmas e ideologias associados a pensamentos de alienação social, pertencentes a uma classe dominante da sociedade, onde pobre é pobre por sua culpa (preguiça, ignorância), por vontade divina ou por inferioridade natural. Destarte, educação é a mudança fundamental de atitudes em busca da promoção do desenvolvimento e da aprendizagem. Segundo Marilena Chauí (2004), a produção ideológica de uma ilusão social, teria como finalidade fazer com que todas as classes sociais aceitassem as condições em que vivem. De forma a julgá-las naturais, justas e corretas, sem nenhuma pretensão de transformá-las ou conhecê-las realmente. Sem sequer levar em conta que há uma imensa contradição entre as condições reais do cotidiano e, as condições ideais que almejamos.

A aprendizagem escolar deve estar associada ao desenvolvimento humano em geral, já que impulsiona o intelecto, o afetivo e o social relacionados à apropriação das mediações culturais da sociedade. O processo educacional é um elemento que leva a dignidade. 
Id on Line Revista Multidisciplinar e de Psicologia

Id on Line Multidisciplinary and Psycology Journal

Outra questão a considerar é a mudança no padrão de gestão quanto à racionalização e a canalização do uso dos recursos já existentes e da aquisição de novos recursos, onde escolas e professores em condições equivalentes sejam responsáveis pelo fracasso e pelo êxito da aprendizagem.

A educação é concretizada no coletivo, assim, a sociedade precisa ser instrumentalizada para demandar ensino de qualidade, portanto é importante estender a preocupação educativa, também, à comunidade local e às famílias, para garantir melhorias na educação.

\section{Finalmente, Apontando Caminhos Possíveis}

A educação básica brasileira não vai conseguir responder aos desafios do século se continuar de costas para o futuro. Ela precisa passar por uma profunda reformulação. Reformulação essa, que não utilize somente insumos básicos isolados, mas que apresente intercorrelação para uma proposta pedagógica cujos objetivos sejam assumidos pela equipe, com responsabilidades compartilhadas.

Faz-se, portanto, necessário promover uma ampla descentralização dos sistemas da educação básica e devolver à escola autonomia de decisão quanto ao seu projeto pedagógico, ou seja, a construção de sua identidade institucional. Autonomia essa que tem como contrapartida a responsabilidade e o compromisso com a aprendizagem do educando.

A descentralização supracitada se constituirá na redefinição do papel das instâncias estatal e intermediária, nas quais se mantém concentrado todo o poder de decisão. A verdadeira descentralização deve se deslocar para a escola.

A interação da escola no seu meio social e a participação ativa da comunidade não devem ser restritas a eleições de diretores, a grêmios estudantis, entre outros, mas da integração de suas experiências com os conteúdos escolares e as práticas dos professores, com papéis diferenciados e definidos ao exercer autonomia e flexibilidade para oferecer atividades de diversa natureza, quando o educando se encontrar ou não no âmbito escolar, adaptadas à realidade local, visando ao atendimento integrado das necessidades.

O protagonismo eficaz do professor, diante da citada necessidade, exige uma formação ininterrupta profissional com estudos e estímulos a experiências diferenciadas. É uma 
Id on Line Revista Multidisciplinar e de Psicologia

Id on Line Multidisciplinary and Psycology Journal

problemática que requer uma intervenção urgente, visto que o professor do século passado são os que estão atuando na sala de aula. Segundo Saviani,

Essa formulação envolve a necessidade de compreender a educação no seu desenvolvimento histórico-objetivo e, por consequência, a possibilidade de se articular uma proposta pedagógica cujo ponto de referencia, cujo compromisso, seja a transformação da sociedade e não sua manutenção, a sua perpetuação. (2008, p.93)

A primordial proposta de intervenção sobre a atual situação seria a de capacitar os docentes para partir do que os alunos sabem e, aos poucos, "aculturá-los", com o objetivo de propiciar-lhes condições de ascensão social, levando em consideração desde fatores fisiológicos até psicológicos, passando por questões sociais, políticas e culturais.

Quem faz o diferencial é o educador, destarte, primordialmente, tem a capacidade de transformar e de encontrar o meio para adentar neste universo enigmático e mágico que é o ser humano e, assim, concretizar ações significativas na prática pedagógica para a efetivação da verdadeira educação.

Para tanto, ajustes deverão ser realizados através de opções políticas de curto prazo, dentre eles, cabe apontar: cursos de habilitação profissional sob a responsabilidade do poder público, sem os quais o professor não está estaria apto a ensinar na rede pública e/ou privada; acompanhamento e capacitação continuados e realizados pela instituição escolar para complementar e/ou corrigir a formação do profissional da educação, em busca de oferecer uma assistência integrada, que adota estratégias inovadoras e adequadas as particularidades do educando; criação de espaços específicos e dedicados à formação do magistério, nos níveis médio e superior; criação de mecanismos de estímulos para os educandos que escolhem o magistério, ao oferecer bolsas de manutenção para permanência integral na escola com atenção individualizada em estágios e disciplinas práticas, que teria como retorno o compromisso de permanecer lecionando por determinado tempo. É preciso priorizar o investimento no nível fundamental, visto que, é uma preparação para a vida e é a base para o ingresso no nível superior, responsável pela mão de obra qualificada no mercado de trabalho.

É imprescindível a reformulação de uma política de qualificação na educação brasileira, sem ela, a educação continuará invisível para a sociedade e pertinente apenas para os educadores e os políticos. 
Id on Line Revista Multidisciplinar e de Psicologia

Id on Line Multidisciplinary and Psycology Journal

\section{Referências}

CHAUÍ, Marilena. Convite a Filosofia - São Paulo - SP: Editora Ática, 2004

FLEURY, Maria Tereza L. e MATTOS, Maria Isabel L. Sistemas educacionais comparados.

KOFFKA, Kurt. Princípios de Psicologia da Gestalt. São Paulo: Cultrix, s.d.

MELLO, Guiomar N. de e SILVA, Rose N. A gestão e a autonomia da escola nas novas propostas de políticas educativas para a América Latina.

MELlO, Guiomar N. de. Social democracia e educação: teses para discussão. São Paulo, Cortez Editora/Editora Autores Associados.

ROGERS, Carl R. Liberdade de aprender em nossa década. Porto Alegre: Artes Médicas,1985.

ROGERS, Carl R. Tornar-se pessoa. $5^{\text {a }}$ ed. São Paulo: Martins Fontes, 2001.

SAVIANI, Dermeval. Escola e Democracia. $8^{a}$ ed. São Paulo, Cortez/Autores Associados, 1985.

SAVIANI, Dermeval. Pedagogia Histórico-Crítica: Primeiras aproximações. $2^{\mathrm{a}}$ ed. São Paulo: Cortez/Autores Associados, 1991.

WOOLFOLK, Anita E. Psicologia da educação. Porto Alegre: Artes Médicas, 2000.

\section{Como citar este artigo (Formato ABNT):}

MAIA, Adriana M.; BESERRA, Theóphilo M.A.C. Polícas Públicas da Educação: Percursos Íngrimes e Sinuosos. Id on Line Revista Multidisciplinar e de Psicologia, Fevereiro de 2017, vol.11, n.34, p. 113-123. ISSN: 19811179 .

Recebido: 24.02.2017

Aceito: 27.02 .2017 